\title{
COVID-19 BASIC REPRODUCTION NUMBER AND ASSESSMENT OF INITIAL SUPPRESSION POLICIES IN COSTA RICA
}

\author{
Luis Fernando Chaves ${ }^{1, *}$, Lisbeth A. Hurtado ${ }^{2}$, \\ Melissa Ramírez Rojas ${ }^{1}$, Mariel D. FriberG ${ }^{3}$, \\ Rodrigo Marín Rodríguez ${ }^{1}$ and María L. Avila-Aguero ${ }^{4,5}$
}

\begin{abstract}
SARS-COV-2 is the most recent from a series of emerging pathogens stressing national health systems. Initially restricted to Hubei province in China, COVID-19, the disease caused by SARS-COV-2 has become pandemic, reaching almost every nation on our planet. Here, we present an estimate of the Basic Reproduction Number $\left(R_{0}\right)$ for this disease based on confirmed cases recorded during the initial 30 days of transmission. Based on local transmission data for the six initial days of transmission, we estimated (mean $\pm \mathrm{SE}$ ) $R_{0}=2.58 \pm 2.43$. $R_{0}$ was reduced by up to $56 \%$ to $R_{0}=1.12 \pm 0.02$ following suppression measures in place by April 4th, 2020. Independent estimates for the time-varying reproduction number $\left(R_{t}\right)$ based on the serial interval distribution estimated for China showed that after 30 days, $R_{t}$ decreased reaching a value of $0.914 \pm 0.104$ on April 4th, 2020. In this study, we also describe the suppression strategies in place in Costa Rica and compare their impacts with those implemented in Panamá and Uruguay, provided these three middle-income countries have similar demographic and economic indicators. However, these three countries have structurally different health systems and have resorted to different suppression measures against COVID-19. We compare the early epidemic growth curves in the three countries using an exponential deceleration model. We found the lowest epidemic growth rate in Costa Rica, followed by Panamá and then Uruguay, while the highest deceleration was observed in Uruguay, followed by Costa Rica and Panamá. We discuss how the unified, universal healthcare system of Costa Rica has been vital to successfully manage the early stage of the COVID-19 epidemic and call for the developments of precision public health tools to further improve epidemic health surveillance in Costa Rica.
\end{abstract}

Mathematics Subject Classification. 62P10, 92B05.

Received April 7, 2020. Accepted May 7, 2020.

Keywords and phrases: Maximum likelihood, trajectory matching, transmission reduction, universal health care.

1 Vigilancia de la Salud, Ministerio de Salud, San José, San José, Costa Rica.

${ }^{2}$ Unidad de Análisis Epidemiológico y Bioestadística, Instituto Conmemorativo Gorgas de Estudios de la Salud, Ciudad de Panamá, Panamá.

${ }^{3}$ Universities Space Research Association, Columbia, MD 21046, USA.

4 Servicio de Infectología, Hospital Nacional de Niños, San José, Costa Rica.

5 Center for Infectious Disease Modeling and Analysis, Yale School of Public Health, New Haven, CT, USA.

* Corresponding author: Ifchavs@gmail.com

(C) The authors. Published by EDP Sciences, 2020 


\section{INTRODUCTION}

Commodity trade, associated with human movement and natural resource extraction (or harvesting), has been linked through time with the emergence of new diseases [15, 29]. Recent epidemics of new and old diseases have become part of everyday news and a notable source of mortality over recent years [6]. Most of these diseases in humans are caused by the spillover of pathogens from other species to humans, and more generally, by changes in the relationship of humans with their surrounding natural environments [31]. In most cases, these epidemics have been very localized in nature [48]. This geographic delimitation has several causes, some related with their transmission by insect vectors of disease, as observed for some alphaviruses and flaviviruses [10, 51], or by their occurrence in places relatively unconnected from global circuits of capital and human movement, as observed for Ebola virus [48, 50].

However, December of 2019 saw the emergence of SARS-CoV-2, a coronavirus of zoonotic origin [4], in Wuhan, Hubei province of China [11]. SARS-CoV-2 is a highly transmissible respiratory virus causing COVID19, a disease that has become pandemic [19]. The first wave of this pandemic has caught countries by surprise, accentuating differences in transmission reduction approaches and public health system structures [20]. Here, we describe and preliminarily evaluate Costa Rica's response to COVID-19 during the month after the country's first detected case. Costa Rica is an interesting case study nation given its decades-long universal health coverage system [22] administered through the Costa Rican Social Security Trust (CCSS, Caja Costarricense de Seguro Social) and based on tripartite contributions from the country's workforce, employers, and the State [36]. The public universal health care and coverage system, led by the Ministry of Health and the CCSS, has been lauded as one of the main reasons for the country's health achievements including extended longevity [40], low childbirth and infant mortality [24], and the expectation of imminent malaria elimination [26].

To assess the impact of the COVID-19 suppression measures [18], we take a three-pronged approach. We start by estimating the basic reproduction number $\left(R_{0}\right)$ of the disease in the country using a simple SusceptibleInfected-Recovered (SIR) model [49] using data collected during the first 30 days of transmission. We then assess the impact of the measures employing a different approach using the time-varying reproduction number $\left(R_{t}\right)$ based on knowledge about the serial interval, i.e., the time between the reporting of infections linked by contact tracing, and other evidence pieces [46]. We employ serial interval estimates from data gathered through interviews used for contact tracing in China [17, 35]. We finish our study by comparing the COVID-19 suppression measures in place in Costa Rica, with those of Panamá and Uruguay, which are countries with similar population size, and social security coverage, but different health delivery systems. We quantify the difference between these countries using a general model for decelerated exponential epidemic growth [48].

\section{DATA AND MODELS}

\subsection{Data}

We collected COVID-19 case data from the Costa Rican Ministry of Health daily bulletins published on their website, where they have also published press releases about the preparation, mitigation, and suppression measures for controlling the COVID-19 epidemic. We collected similar information for Panamá and Uruguay, two other middle-income Latin American nations where the COVID-19 pandemic started in early March. Despite many similarities between the three countries, their health care systems are structurally different. The publicly available COVID-19 case data for Costa Rica, Panamá, and Uruguay are at ministeriodesalud.go.cr/index.php/centro-de-prensa/noticias/741-noticias-2020/1532lineamientos-nacionales-para-la-vigilancia-de-la-infeccion-por-coronavirus-2019-ncov, tinyurl.com/qvclxco, and gub.uy/sistema-nacional-emergencias/comunicacion/comunicados, respectively. Figure 1 shows the COVID-19 epidemic data. Specifically, Figure 1A shows the number of daily cases reported in Costa Rica, whereas Figure 1B shows the cumulative number of cases in Costa Rica, Panamá, and Uruguay.

COVID-19 was first brought to the international community's attention as a highly contagious and lethal respiratory virus in early February 2020. Since then, the Costa Rican Ministry of Health and the CCSS have been pro-actively making recommendations targeting the entire country's population through mass-media public 

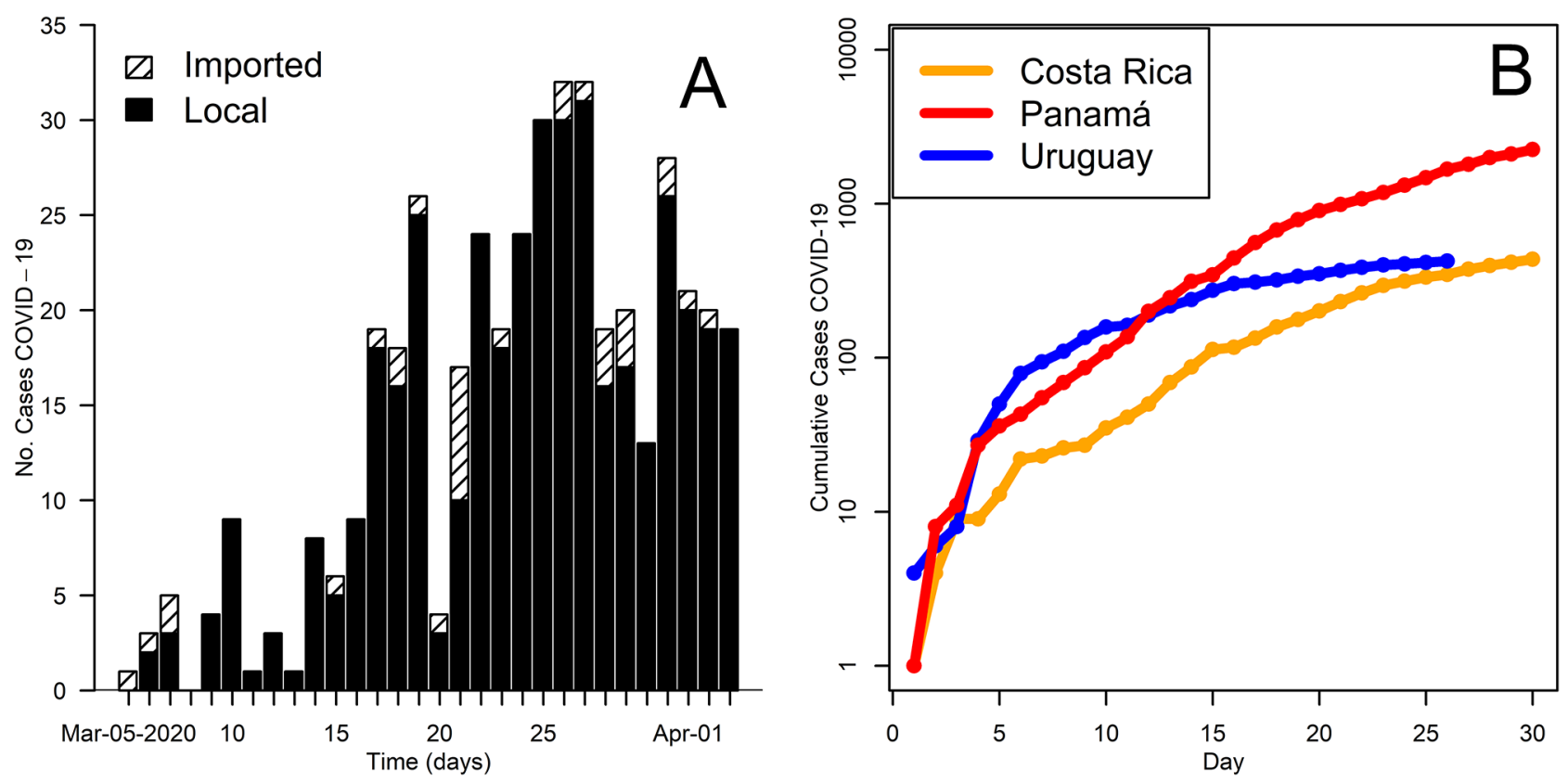

Figure 1. Number of COVID-19 Cases. (A) Reported daily cases in Costa Rica, separated by their origin as local or imported. (B) Cumulative cases, including imported and local, for Costa Rica, Panamá and Uruguay. The $y$-axis is on a logarithmic scale, and day 1 is March 5 th for Costa Rica, March 6th for Panamá, and March 10th for Uruguay.

educational campaigns to reduce transmission of respiratory viruses before the country's first COVID-19 case detection. This communication effort was succeeded by incremental mitigation, i.e., targeting the diagnosed and symptomatic population, and suppression, i.e., targeting the entire population, measures. Table 1 describes the timeline of the different measures aimed at reducing SARS-CoV-2 transmission in Costa Rica. We divided these control measures into three main phases. The first phase, referred to as Preparation and Mitigation in Table 1, spanned from February 3rd to March 10th and consisted of preparation for the SARS-CoV-2 arrival and initial mitigation following initial cases. The second or initial suppression phase, referred to as Suppression I in Table 1, was characterized by the recommendation and partial enforcement of physical distancing from March 11th to March 19th. An enhanced suppression phase, referred to as Suppression II in Table 1, included steadily increasing enforcement of physical distancing from March 23rd to the present.

We also collected data on key demographic, economic, and health coverage and access indicators, as well as COVID-19 diagnostic coverage for the three countries. Table 2 shows the data and their respective sources. Of the three countries, Costa Rica has the largest population size, followed by Panamá and then Uruguay. Uruguay has the highest proportion of the population that is 65 years or older, which has the highest risk of clinical complications by COVID-19 [54, 55], followed by Costa Rica and then, Panamá. Regarding COVID-19 tests, Panamá leads with the highest number of diagnostic tests, followed by Uruguay, and lastly, Costa Rica. The percentage of people with health insurance coverage is similar among the three countries at approximately $80 \%$. The GDP per capita is highest in Uruguay, followed by Panamá and then Costa Rica. As measured by the GINI index, the Uruguayan society is the most equitable, followed by Costa Rica and then, by Panamá. Costa Rica's CCSS is in charge of collecting the tripartite contributions to fund the universal healthcare system, in addition to managing and administering all public centers for health care delivery [41, 43]. In contrast, Panamá [42] and Uruguay [5] have segmented health systems, where several autonomous institutions are in charge of public centers for health care delivery [43]. 
TABLE 1. Timeline for COVID-19 preparation, mitigation and suppression measures in Costa Rica up to April 4th, 2020. Suppression measures are expected to reduce transmission more than mitigation measures. The impact of such measures on SARS-CoV-2 is not related to the implementation date but adherence, population coverage, and effectiveness to increase physical distancing.

\begin{tabular}{|c|c|c|}
\hline Phase & Date & Measure \\
\hline \multirow[t]{5}{*}{$\begin{array}{l}\text { Preparation and } \\
\text { mitigation }\end{array}$} & $\begin{array}{l}\text { February } \\
3-\text { March } 3\end{array}$ & $\begin{array}{l}\text { Simulation of the emergency situation following the detection } \\
\text { of COVID-19 cases, recommendation for churches to reduce } \\
\text { the contact between hands and mouth during religious services. } \\
\text { General recommendations about improved hygiene, including } \\
\text { frequent hand washing, covering the nose with the forearm while } \\
\text { sniffing and avoiding touching the head, mouth and nose when } \\
\text { hands have not been previously washed }\end{array}$ \\
\hline & March 5 & $\begin{array}{l}\text { First imported COVID-19 case, a mildly symptomatic tourist } \\
\text { coming from the United States. Quarantine of people with } \\
\text { detected infections }\end{array}$ \\
\hline & March 8 & $\begin{array}{l}\text { Recommendation for delaying international travel to Costa } \\
\text { Rican Citizens }\end{array}$ \\
\hline & March 9 & $\begin{array}{l}\text { Work at home for public employees who can perform work duties } \\
\text { from home. Closure of schools where students have been in } \\
\text { contact with SARS-CoV-2 infected people }\end{array}$ \\
\hline & March 10 & $\begin{array}{l}\text { Suspension of events with large concentrations of people, some } \\
\text { public reunion places can still be open provided they comply } \\
\text { with strict disinfection protocols }\end{array}$ \\
\hline \multirow[t]{3}{*}{ Suppression I } & March 11 & Encouragement of physical distancing \\
\hline & March 12 & $\begin{array}{l}\text { Reduction by } 50 \% \text { of capacity in public use spaces to } \\
\text { ensure physical distancing, international travel ban for public } \\
\text { employees }\end{array}$ \\
\hline & March 15-19 & $\begin{array}{l}\text { Closure of public spaces, suspension of classes at all levels and } \\
\text { closure of international borders to non-citizens or legal residents. } \\
\text { On March } 16^{t h} \text {, the president and health minister declare a } \\
\text { national emergency, through executive bill } 42227 \text {-MP-S }\end{array}$ \\
\hline \multirow[t]{2}{*}{ Suppression II } & March 23-27 & $\begin{array}{l}\text { Vehicular transit restriction for cars between } 10 \mathrm{pm}(8 \mathrm{pm} \text { on } \\
\text { weekends) and } 5 \mathrm{am} \text {. Closure of all beaches and religious temples }\end{array}$ \\
\hline & April 1 & $\begin{array}{l}\text { Free transit forbidden between } 5 \text { pm and } 5 \text { am. All long distance } \\
\text { public transportation (between different cities or metropolitan } \\
\text { areas) is forbidden; free transit of private cars furtherly banned, } \\
\text { on a day by day basis, based on the last number of the car plate }\end{array}$ \\
\hline
\end{tabular}

\subsection{Models}

\subsection{1. $R_{0}$ estimation based on the SIR model}

To estimate the basic reproduction number of SARS-CoV-2 in Costa Rica we used a SIR model without demography, i.e., assuming a constant population size [2], denoted by $N$. The major model assumptions are that upon infection cases are immediately observed, and that upon recovery, individuals are immune for the rest of their lives. The transmission is assumed to be driven by a mass action principle, where new infections are proportional to the number of infected and susceptible hosts at any given time [2]. This model is described 
TABle 2. Demographic, economic, health coverage indicators and COVID-19 diagnostics numbers in Costa Rica, Panamá and Uruguay.

\begin{tabular}{|c|c|c|c|}
\hline Country & Costa Rica & Panamá & Uruguay \\
\hline $\begin{array}{l}\text { Population size (July } 2019) \\
\text { GDP per capita }(2019)^{4} \\
\text { Gini Index } 2018^{5} \\
\text { Social Security and Health Delivery Model } \\
\text { Social Security Coverage }(\%) \\
\text { Universal health-care coverage }(\%)^{6} \\
\text { Population aged } \geq 65 \text { years } 2019(\%) \\
\text { Cumulative number of COVID-19 diagnos- } \\
\text { tics tests by April } 4 \text { th } 2020\end{array}$ & $\begin{array}{l}5058007^{1} \\
12027.4 \\
49.3 \\
\text { Unified } \\
85^{1} \\
77 \\
10^{1} \\
4238(31 \text { days })^{7}\end{array}$ & $\begin{array}{l}4159000^{2} \\
15575.1 \\
49.8 \\
\text { Segmented } \\
75^{2} \\
79 \\
8^{2} \\
9699(30 \text { days })^{8}\end{array}$ & $\begin{array}{l}3518522^{3} \\
17278.0 \\
39.5 \\
\text { Segmented } \\
97^{3} \\
80 \\
14^{3} \\
5063(23 \text { days })^{9}\end{array}$ \\
\hline $\begin{array}{l}{ }_{1} \text { inec.cr/poblacion/estimaciones-y-proyecciones-d } \\
{ }^{2} \text { inec.gob.pa/publicaciones/Default3.aspx?ID_PU } \\
{ }^{3} \text { ine.gub.uy/web/guest/indicadores-demograficos } \\
{ }^{4} \text { datos.bancomundial.org/indicador/NY.GDP.PC } \\
{ }^{5} \text { repositorio.cepal.org/bitstream/handle/11362/4 } \\
{ }^{6} \text { datos.bancomundial.org/indicador/SH.UHC.SRV } \\
{ }^{7} \text { tinyurl.com/svakdvp } \\
{ }^{8} \text { minsa.gob.pa/informacion-salud/comunicados-c } \\
9^{9}\end{array}$ & $\begin{array}{l}\text { blacion } \\
\text { CACION=499\&ID } \\
\text { CD?locations=ZJ } \\
\text { /5/S1901133_es.p } \\
\text { V.XD }\end{array}$ & (1) & \\
\hline
\end{tabular}

by the following system of three ordinary differential equations:

$$
\begin{aligned}
\frac{\mathrm{d} S}{\mathrm{~d} t} & =-\beta \frac{S}{N} I \\
\frac{\mathrm{d} I}{\mathrm{~d} t} & =\beta \frac{S}{N} I-\gamma I \\
\frac{\mathrm{d} R}{\mathrm{~d} t} & =\gamma I .
\end{aligned}
$$

This model has been widely studied, and it is known that infection number will grow when the transmission rate, $\beta$, is larger than the recovery rate, $\gamma$, in equation (2.1). The ratio between these two parameters is the basic reproduction number, $R_{0}$ :

$$
R_{0}=\frac{\beta}{\gamma}
$$

Which sets the condition for epidemic establishment when its value is above 1 , i.e., $R_{0}>1$ [1]. Although this might not be the best representation for the transmission dynamics of SARS-CoV-2 [49] the model has the advantage of making no assumptions about the incubation period, and other unknown transmission parameters, and can be easily fit using maximum likelihood methods based on trajectory matching of observed data [7]. Moreover, this approach can easily and quickly produce estimates of the peak number of infected individuals at any given time and the time to reach the peak of infections under different dynamical regimes of transmission [18]. This model has been used by policy and decision-makers in Costa Rica to evaluate the impact of transmission "mitigation" or "suppression" strategies and to evaluate whether the different measures have been able 
to "flatten" the epidemic curve [3] reducing the burden of COVID-19 on the Costa Rican health system and projecting immediate to mid-term healthcare needs. Here, we use daily records of locally transmitted COVID-19 from Costa Rica to fit the model presented in (2.1), accounting for "breakpoints" that follow, with a delay, the "suppression" strategies presented in Table 1 . The delay biologically represents both the implementation and adherence of mitigation policies by the population and the delay that might emerge from the COVID-19 incubation period. To fit the SIR model we used data only from the local cases, and our maximum likelihood function assumed that any stochasticity was due to observation error $(\varepsilon)$, for example, not detecting cases. The error was assumed to be independently, identically, and normally distributed with mean zero and constant variance $\left(\sigma^{2}\right)$, i.e., $\varepsilon \sim N\left(0, \sigma^{2}\right)$. We estimated initial parameters for the maximum likelihood fit using a genetic algorithm (GA) [44] constraining parameter search between 0 and 1 for both parameters $\beta$ and $\gamma$. For the GA, we employed as fitness function the normal maximum likelihood, using an initial population of 50 individuals and iterated the algorithm 100000 times, a recombination rate of 0.8 , and a mutation rate of 0.1 . We then fitted the model using the maximum likelihood function using the command "mle2" from the R package "bbmle" [8] employing as initial conditions the global minimum found with the GA and performing a local constrained optimization between 0 and 1 using the function-gradient quasi-Newton box constrained limited memory algorithm [9].

Assuming the mitigation and suppression measures reduced transmission, we fitted a model for the 30 days of data that we consider in this study, but we also split model fitting on days following changes in the mitigation and suppression measures. This strategy improved the model fit but also increased the number of parameters, provided parameters are estimated for each segment. In order to test this procedure for spurious overfitting, we compared the Akaike Information Criterion (AIC), which trade-offs model goodness of fit and parameter number [25]. AIC is minimized by the best model [25]. Thus, we compared the AIC of split and complete models to ensure the split models were outperforming a model fitted with the entire time series of cumulative COVID-19 cases. The model fitting the entire time series assumes the mitigation and suppression measures has no impact reducing SARS-CoV-2 transmission, a strategy we have previously used when evaluating regime shifts in disease transmission [12].

\subsection{2. $R_{t}$ estimation based on the serial interval}

As a second modeling approach to measuring the impact of the suppression strategies, we used the timevarying reproduction number $\left(R_{t}\right)$. Similar to $R_{0}, R_{t}$ measures the expected number of new cases generated by a given case, but without assuming the entire population is susceptible to the disease and only considering the serial interval, i.e., the time distribution between the symptom onset in an initial case and symptom onset in secondary cases linked by contact tracing to that initial case [46]. Since contact tracing data is still being processed in Costa Rica, awaiting ethical clearance for public release, we used estimates from China [17], which to date, are based on the largest sample size, and were built considering that transmission occurs at least one ten of the times before the originating infected person shows any symptoms [17]. To consider potential transmission uncertainties, we estimated $R_{t}$ using a method that accounts for uncertainties developed by Thompson et al. [46] where we took full advantage of the parameter estimates presented by Du et al. [17], which allowed us to set the $95 \%$ credible intervals from their estimates as the minimum and maximum values for the mean and SD of the serial interval, while also setting a standard deviation of 0.2 . Also, when estimating $R_{t}$, we used the method that considers imported cases as potentially generating new infections, but that does not consider them as part of the local transmission, thus reducing bias sources in the estimation of $R_{t}$ [46]. We estimated $R_{t}$ using the $\mathrm{R}$ package "EpiEstim" [46]. This second approach allowed us to have an independent estimate of the COVID-19 reproduction number, using a different set of assumptions, and also to evaluate how robust were the estimates of the suppression measures in place in Costa Rica, as measured with the SIR model.

\subsubsection{Comparison of early epidemic growth in Costa Rica, Panamá and Uruguay using a general growth curve}

A third modeling approach was to compare the initial growth curve of Costa Rica with that of Panamá and Uruguay. All of which are middle-income Latin-American countries based on their GDP per capita, have similar 
universal health coverage indices, but have differing suppression strategies to reduce SARS-CoV-2 transmission, as well as structurally different health care systems (Tab. 2). This strategy allowed us to compare if some of the impacts of the suppression measures might have been aided by the structure of the Costa Rican health system. We compared the early ascending phase of COVID-19 epidemic growth among the three countries using a generalized-growth model to characterize outbreaks, which is based on the following ordinary differential equation [48]:

$$
\frac{\mathrm{d} C(t)}{\mathrm{d} t}=r C(t)^{p} .
$$

Where $C(t)$ is the cumulative number of cases at time $t$ after the outbreak started, $r$ is a parameter for case growth rate and assumed to be positive, i.e., $r>0$, and $p$ is a parameter related to the case growth rate. When $p=0$, cases increase at a constant rate, when $p=1$ case growth follows perfect exponential growth curve and when $0<p<1$ the model has sub-exponential growth, and equation (2.3) can be solved as follows [47]:

$$
C(t)=\left(\frac{r}{m} t+A\right), m
$$

where $A$ depends on the initial condition $C(0)$ and $m>1$ is related to $p$ as follows:

$$
p=1-\frac{1}{m}
$$

From where it follows that parameter $m$ should decrease as suppression measures reduce COVID-19 cases, while parameters $r$ and $A$ likely reflect structural differences in the health systems. To fit the model presented in equation (2.4) we used the "mle2" command from the R package "bbmle" [8] and a Poisson maximum likelihood function, where we used a GA as described for the SIR model for the initial parameter search. Then a local optimization was performed using the Nelder-Mead algorithm [34], and confidence intervals were estimated by profiling the likelihood for each parameter [8].

\section{Results And Discussion}

Results for the SIR model are presented in Figure 2. The very first days of the epidemic, suggested a relatively high $R_{0}$ with an estimate of 2.58, which presented some transients that settled on a curve with a $R_{0}$ of 1.78. Coinciding with the start of the Suppression I phase $R_{0}$ was furtherly decreased to 1.27 when a split model was fit for March 19th, and $R_{0}$ went further down to 1.12 after the start of the Suppression II phase. In conjunction these results suggest that mitigation and suppression measures have been highly successful at reducing SARS-CoV-2 transmission, provided $R_{0}$ has been drastically reduced to less than half of its original estimate. The process of AIC based model selection confirmed that the split model (AIC = 197.00) outperformed a model with just one split on March 19th $(\mathrm{AIC}=255.27)$ or March 28th $(\mathrm{AIC}=344.75)$, and also a model without splits $(\mathrm{AIC}=422.76)$. These changes in $R_{0}$ have drastic impacts on the number of cases and the time to reach the epidemic peak (Fig. 2B). For example, when $R_{0}=2.58$ the maximum number of cases was expected to be 1247120 occurring 35 days after March 6th. With $R_{0}=1.78$, the epidemic maximum number cases is reduced to 580041 occurring 40 days after the start of the epidemic. With $R_{0}=1.27$, the epidemic maximum number cases is reduced to 127134 occurring 67 days after the start of the epidemic. With $R_{0}=1.12$, the epidemic maximum number cases is reduced to 28755 occurring 111 days after the start of the epidemic. This last scenario leads to a maximum expected number of 1438 cases requiring medical attention by presenting critical clinical complications, assuming a 5\%, and 288 deaths assuming $20 \%$ of the critical cases die. However, this approach might be overestimating transmission, since by splitting the time series the fits assume all the population is unexposed to SARS-CoV-2. In other words, $R_{0}$ estimates based on data segments after 

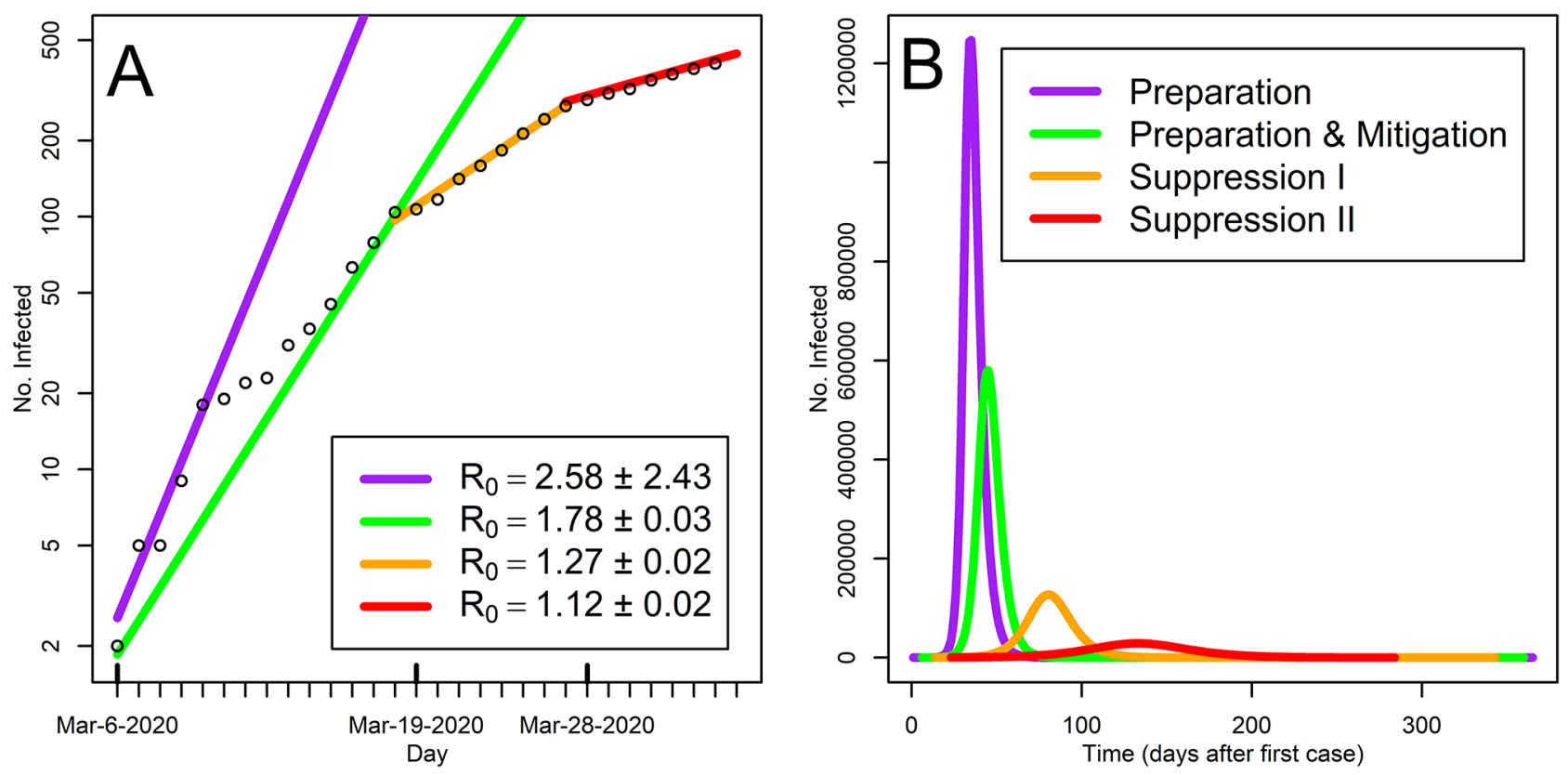

Figure 2. SIR model results. (A) Model fits and $R_{0}$ estimates \pm SE. (B) Curves for the number of infected individuals under different COVID-19 control measures. These curves are presented to illustrate the trade-off that emerges from flattening the transmission curve, where the number of cases at any time decreases, but the epidemic duration increases. In both panels, colors indicate the different control phases presented in Table 1.

March 19th, assume the whole population is susceptible, despite the extended period of transmission, and the possibility of inapparent or asymptomatic infections [33]. In addition, we do not consider potential uncertainties in our estimates and base our predictions on the deterministic solution of the ordinary differential equation system presented in equation (2.1). We also do not explore other simple models of transmission that include an incubation period that can be modeled by including an exposed class [56], or by including time delays [49], or considering heterogeneities arising from mobility of infected people [23]. Nevertheless, our results illustrate that flattening the curve increases the duration of the epidemic, yet it maximizes the number of averted deaths $[3,18]$ and that physical distancing significantly reduced transmission in Costa Rica, as observed in China [45] and Singapore [27].

The distribution of simulated serial intervals used to estimate $R_{t}$ for Costa Rica are presented in Figure 3A. We used this approach as data from Costa Rican patients is still being processed and going through ethical clearance for their anonymized release, but also to consider potential differences between the symptomatology observed in China and in Costa Rica. Figure 3B shows daily $R_{t}$ estimates for Costa Rica, which currently are not significantly different from $1, R_{t}(95 \%$ credible intervals $)=0.914(0.721,1.130)$, meaning the number of arriving cases is expected to remain constant between 14 and 30 daily cases. Looking at the $R_{t}$ evolution through time Figure 3B shows that suppression measures have been likely key to reduce transmission, provided that before those measures $R_{t}$ was significantly above 1 , which implies an increase likelihood of entering an accelerated growth of COVID-19 cases, and that after the start of the "Suppression II" phase $R_{t}$ has become stable around 1. Interestingly this analysis gives some robustness, in the sense that methods with different assumptions reach the same conclusions [28], to the inferences based on the SIR model, which suggest the incremental mitigation and suppression measures have significantly reduced SARS-CoV-2 transmission, averting a significant number of infections, as well as, cases with clinical complications and deaths. 

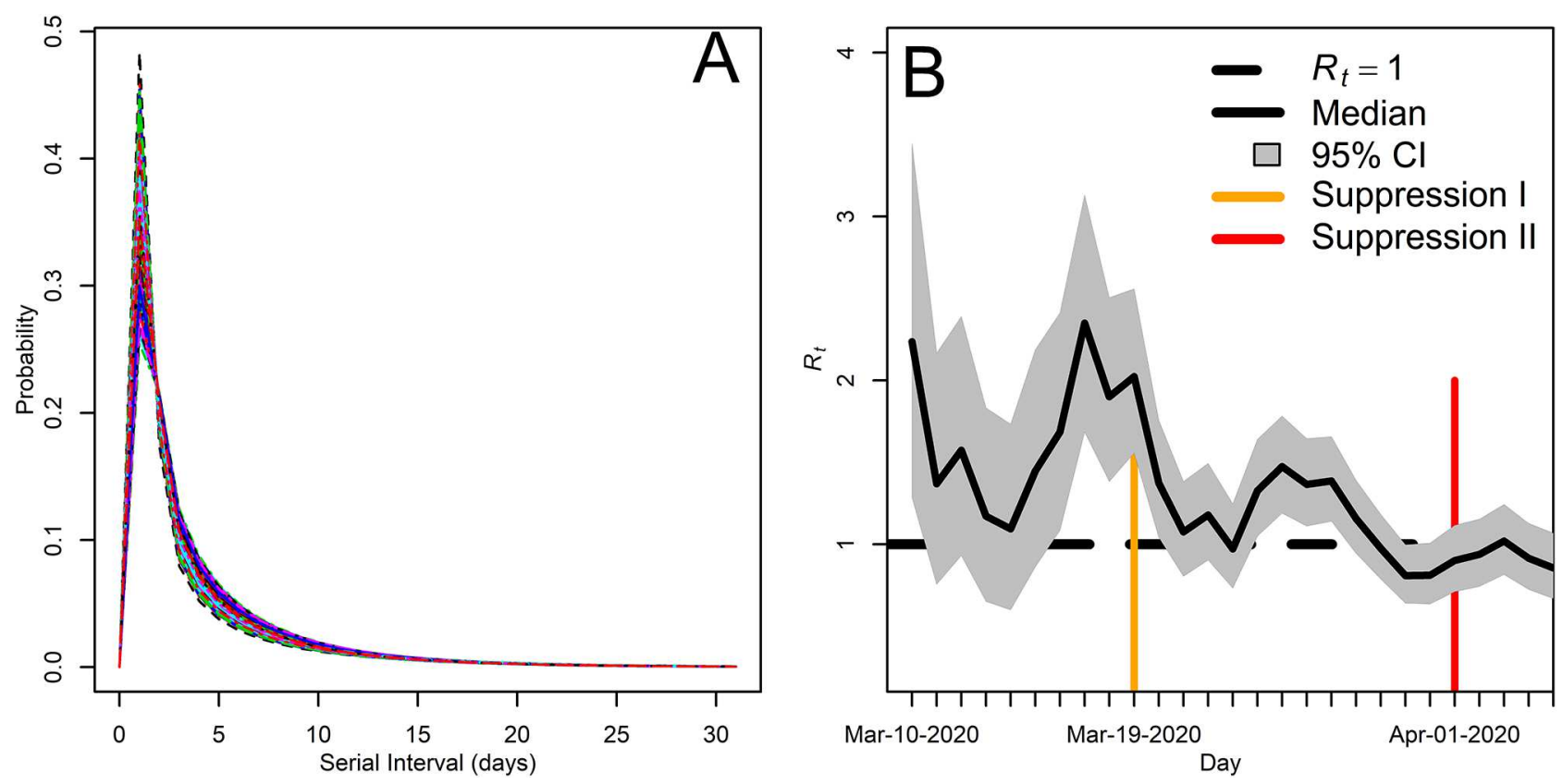

Figure 3. Serial interval and daily $R_{t}$ estimates. (A) Simulated serial intervals based on the mean $=3.96$ days and $\mathrm{SD}=4.75$ days estimated by $\mathrm{Du}$ et al. [17]. For the simulations, used to assess uncertainties in the estimates, we assumed a minimum mean $=3.53$ and a maximum mean $=4.39$ days, and a minimum $\mathrm{SD}=4.46$ and maximum $\mathrm{SD}=5.07$ days, which were based on the $95 \%$ credible intervals of the distribution estimated by Du et al. [17]. Each color line indicates a realization. For the simulations in the panel, we assumed a SD of 0.2 for the mean and variance, and we observed no major difference when increasing the SD to 1. (B) Daily $R_{t}$ intervals, the horizontal dashed black line is the threshold when $R_{t}=1$, while vertical lines indicate the start of the COVID-19 suppression phases I and II described in Table 1.

Finally, the third approach to understanding the impact of the mitigation and suppression measures to reduce COVID-19 cases is the comparison of early epidemic growth parameters for Costa Rica (Fig. 4A) with Panamá (Fig. 4B) and Uruguay (Fig. 4C). Three countries with similar health indicators, but structurally different health systems, patterns of socio economic inequity across their population and response to the epidemic in terms of epidemic surveillance (Tab. 2). First, to date the country that has had the best result with the ultimate negative outcome of the COVID-19 pandemic is Costa Rica, which so far, as of April 5th, 2020, only has had two deaths due to COVID-19 when compared with the four reported by Uruguay and 57 reported by Panamá. In a sense, this might reflect structural differences in the health care delivery system of the three countries, where only Costa Rica has a unified and universal health coverage system that increases the likelihood of patients needing healthcare to seek medical services without worries about future debts or lack of access to medical services by lack of service coverage [30, 42, 53]. The curves also show that the epidemic growth parameter $r$, was lowest for Costa Rica (Fig. 4A) as compared to Panamá (Fig. 4B) and Uruguay (Fig. 4C), indicating the potential for exponential epidemic growth in Costa Rica was smaller and likely associated with its preparedness for the epidemic, as suggested by actions performed since February in response to the potential arrival of SARS-CoV-2 (Tab. 1). However, the deceleration of the epidemic growth was highest in Uruguay (lowest $m$ ), suggesting social equity and background conditions that allow the practice of voluntary physical distancing, are more effective than enforced measures, as implemented in Costa Rica, and which have been even more strict in Panamá where human mobility, through a lockdown, is strictly limited and enforced by the police. 

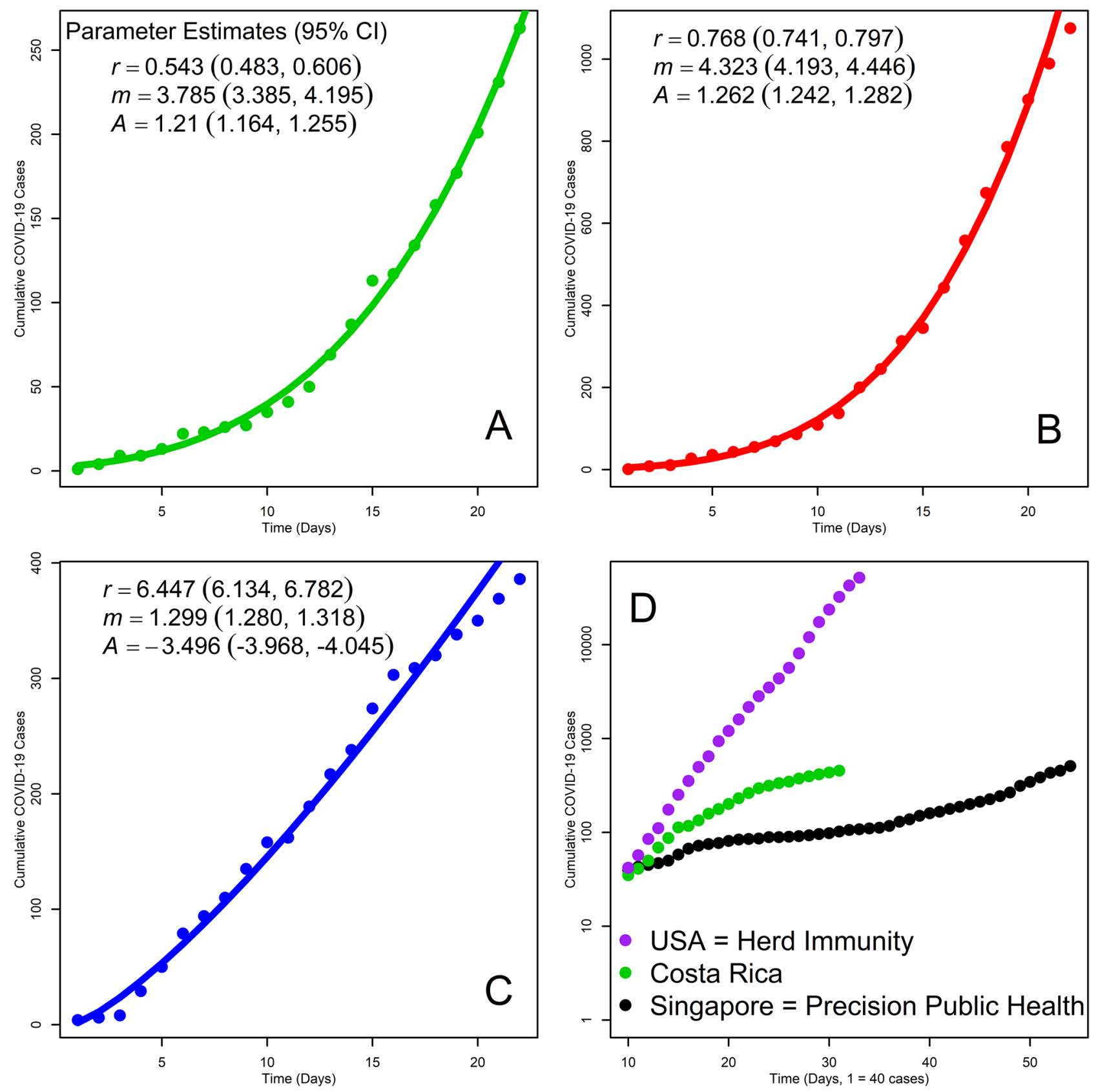

Figure 4. Early epidemic growth curves. (A) Costa Rica, (B) Panamá, (C) Uruguay, (D) USA, Costa Rica and Singapore ( $y$-axis is in log scale, and the first day on the $x$-axis is when cases approached 40, which in Costa Rica was day 10 after the first case detection). In panels A, B and $\mathrm{C}$ curves are based on maximum likelihood parameter estimates, inset in each panel with their $95 \%$ confidence intervals, for the early epidemic growth model of equation (4). In panel (D) data from Singapore and the USA were obtained from coronavirus.jhu.edu/data. 
Meanwhile, Panamá has had the highest number of delivered diagnostic tests (Tab. 2), an effort led by its national reference laboratory, the Gorgas Memorial Institute. Panamá has also taken the lead in Mesoamerica, regarding laboratory-based COVID-19 epidemic surveillance, by developing their own "in house" diagnostic tools [37], delivering the highest number of diagnostics per capita across studied nations here (Tab. 2), but also in Latin America [14]. Furthermore, the Gorgas Memorial Institute has been able to isolate SARS-CoV-2 strains circulating in Panamá and sequence their full genome using this information for cluster reconstruction and to study different clinical manifestations of SARS-CoV-2 strains [37]. This cutting edge laboratory-based epidemic surveillance is necessary to gain insights for the practice of precision public health, which considers detailed molecular and mathematical modeling predictions for policy- and decision-making to more efficiently reduce infectious disease transmission [16].

As a result of the measures, transmission decreased and the geographic extent of COVID-19 in Costa Rica is very limited. However, the country is highly vulnerable to increases in transmission if adherence to physical distancing decreases. An occurrence possibly triggered by a perception that COVID-19 is not a major health threat by its low incidence, a phenomenon observed, for example, with community-based vector control for dengue [38] and insecticide treated nets for malaria control in Sub-Saharan Africa [21]. Another threat is mass human movement from migrant workers from neighboring countries, notably Nicaragua, especially during Easter, a major holiday in all Mesoamerican nations when people usually return home to see their family. In that sense, it is fundamental to keep an increased focalized epidemic surveillance for COVID-19 cases, and despite the initial success we describe here, use the precautionary principle, keeping physical distancing suppression measures in place until the pandemic recedes globally, to minimize the risk of an explosion in transmission.

\section{Conclusions}

Our preliminary analysis robustly suggests that suppression and mitigation measures have been effective in Costa Rica, potentially averting many COVID-19 cases and deaths from this emerging pathogen. From a wider perspective, Costa Rica lies in the middle of the observed scenarios regarding the COVID-19 pandemic handling by national health systems, between the extremes represented by USA and Singapore (Fig. 4D). On one extreme we have the USA, which during the first weeks of the epidemic did not attempt to mitigate, or suppress SARSCoV-2 transmission, favoring the "endemic stability" scenario used for decision making in the management of domestic animal farms to maximize economic profit [13], as it rapidly creates "herd immunity" in the population thus reducing the time where "productive" activities are curbed by suppression measures. On the other extreme, there is Singapore, where a highly developed epidemic surveillance system, geared towards "precision public health" [16], has been performing cutting edge laboratory based epidemic surveillance to quickly tackle and interrupt transmission chains keeping transmission very low, as transmission clusters are quickly identified based on "state of the art" molecular diagnostics [39], without needing to scale up suppression measures, and keeping productive activities going [27, 52]. In Costa Rica, given these two extremes, the optimization based on ensuring public health, ultimately avoiding deaths [32], promoting health as opposed to curing the sick, has ruled the policy- and decision-making process to curb COVID-19 incidence. To further increase the odds for achieving these goals, the comparison of Costa Rica with similar Latin American nations reveals the potential to enhance the Costa Rican epidemic surveillance system developing a national reference laboratory able to develop tools for precision public health. This is a reachable goal, as successfully demonstrated by the Gorgas Memorial Institute in Panamá. Similarly, Costa Rica can also pursue the wider goal of reducing and reverting current increasing trends of socio-economic inequity [57, 58], so that, when necessary, voluntary measures for physical distancing, or other disease control measures, can be easily implemented by the population without the need to enforce them, as observed in Uruguay.

Acknowledgements. This study received no specific funding, however, the work by LFC and LAH was partially funded by Project COVID-19-226 from SENACYT, Panamá. All authors declare that no competing interests exist. 


\section{REFERENCES}

[1] R.M. Anderson, Populations and infectious diseases: ecology or epidemiology? J. Animal Ecol 60 (1991) 1-50.

[2] R.M. Anderson and R.N. May, Infectious diseases of humans: dynamics and control. Oxford University Press, Oxford (1991).

[3] R.M. Anderson, H. Heesterbeek, D. Klinkenberg and T.D. Hollingsworth, How will country-based mitigation measures influence the course of the COVID-19 epidemic? Lancet 395 (2020) 931-934.

[4] K.G. Andersen, A. Rambaut, W.I. Lipkin, E.C. Holmes and R.F. Garry, The proximal origin of SARS-CoV-2. Nat. Med. 26 (2020) $1-3$.

[5] D. Aran and H. Laca, Sistema de salud de Uruguay. Salud Pública de México 53 (2011) s265-s274.

[6] E.D. Belay and S.S. Monroe, Low-incidence, high-consequence pathogens. Emerg. Infect. Dis. 20 (2014) $319-321$.

[7] O.N. Bjørnstad, Epidemics Models and Data using R. Springer, Cham, Switzerland (2018).

[8] B.M. Bolker, Ecological Models and Data in R. Princeton University Press, Princeton (2008).

[9] R.H. Byrd, P. Lu, P. Nocedal and C. Zhu, A limited memory algorithm for bound constrained optimization. SIAM J. Sci. Comput. 16 (1995) 1190-1208.

[10] J.-P. Carrera, N. Forrester, E. Wang, A.Y. Vittor, A.D. Haddow, S. López-Vergès, I. Abadía, E. Castaño, N. Sosa, C. Báez, et al., Eastern equine encephalitis in Latin America. New Eng. J. Med. 369 (2013) 732-744.

[11] JF.-W. Chan, S. Yuan, K.-H. Kok, KK.-W. To, H. Chu, J. Yang, F. Xing, J. Liu, CC.-Y. Yip and RW.-S. Poon, A familial cluster of pneumonia associated with the 2019 novel coronavirus indicating person-to-person transmission: a study of a family cluster. The Lancet 395 (2020) 514-523.

[12] L.F. Chaves, M. Ramírez Rojas, M. Prado, J.L. Garcés, D. Salas Peraza and R. Marín Rodríguez, Health policy impacts on malaria transmission in Costa Rica. To appear in: Parasitology https://doi.org/10.1017/S0031182020000621 (2020).

[13] P.G. Coleman, B.D. Perry and M.E.J. Woolhouse, Endemic stability-a veterinary idea applied to human public health. Lancet 357 (2001) 1284-1286.

[14] COVID-19 Testing Trends - Globally \& Regionally. Available at: https://www.healthpolicy-watch.org/covid-19-testing-trendsglobally-regionally/ (2020).

[15] A.P. Dobson and E.R. Carper, Infectious diseases and human population history: throughout history the establishment of disease has been a side effect of the growth of civilization. BioScience 46 (1996) 115-126.

[16] S.F. Dowell, D. Blazes and S. Desmond-Hellmann, Four steps to precision public health. Nature 540 (2016) 189.

[17] Z. Du, X. Xu, Y. Wu, L. Wang, B.J. Cowling and L.A. Meyers, Serial Interval of COVID-19 among Publicly Reported Confirmed Cases. To appear in: Emerg. Infect. Dis. 26 https://doi.org/10.3201/eid2606.200357 (2020).

[18] N. Ferguson, D. Laydon, G. Nedjati Gilani, N. Imai, K. Ainslie, M. Baguelin, S. Bhatia, A. Boonyasiri, Z. Cucunuba Perez and G. Cuomo-Dannenburg, Report 9: Impact of non-pharmaceutical interventions (NPIs) to reduce COVID-19 mortality and healthcare demand (2020).

[19] B. Gates, Responding to Covid-19 - A Once-in-a-Century Pandemic? N. Eng. J. Med. 382 (2020) $1677-1679$.

[20] J. Hopman, B. Allegranzi and S. Mehtar, Managing COVID-19 in Low- and Middle-Income Countries. JAMA 323 (2020) $1549-1550$

[21] K. Honjo, L.F. Chaves, A. Satake, A. Kaneko and N. Minakawa, When they don't bite, we smell money: Understanding malaria bednet misuse. Parasitology 140 (2013) 580-586.

[22] F.M. Knaul, A. Bhadelia, H.A. Ornelas, L. de Lima and Md.R. Sáenz Madrigal, Closing the pain divide: the quest for effective universal health coverage. Lancet Global Health 3 (2015) S35.

[23] M.U.G. Kraemer, C.-H. Yang, B. Gutierrez, C.-H. Wu, B. Klein, D.M. Pigott, L. du Plessis, N.R. Faria, R. Li and W.P. Hanage, et al., The effect of human mobility and control measures on the COVID-19 epidemic in China. Science 368 (2020) eabb4218.

[24] M.E. Kruk, A.D. Gage, N.T. Joseph, G. Danaei, S. García-Saisó and J.A. Salomon. Mortality due to low-quality health systems in the universal health coverage era: a systematic analysis of amenable deaths in 137 countries. Lancet 392 (2018) $2203-2212$.

[25] M. Kuhn and K. Johnson, Applied Predictive Modeling. Springer, New York (2013).

[26] R. Marín Rodríguez and L.F. Chaves, Parasite Removal for Malaria Elimination in Costa Rica. Trends Parasitol. 35 (2019) $585-588$.

[27] V.J. Lee, C.J. Chiew and W.X. Khong, Interrupting transmission of COVID-19: lessons from containment efforts in Singapore. To appear in: J. Travel Med. https://doi.org/10.1093/jtm/taaa039 (2020).

[28] R. Levins, Evolution in Changing Environments. Some theoretical explorations. Princeton University Press, Princeton (1968).

[29] R. Levins, Toward an integrated epidemiology. Trends Ecol. Evol. 10 (1995) 304.

[30] R. Levins and C. Lopez, Toward an ecosocial view of health. Int. J. Health Serv. 29 (1999) 261-293.

[31] R. Levins, T. Awerbuch, U. Brinkmann, I. Eckardt, P. Epstein, N. Makhoul, C.A. Depossas, C. Puccia, A. Spielman and M.E. Wilson, The emergence of new diseases. Am. Sci. 82 (1994) 52-60.

[32] R. Lewontin and R. Levins, Let the numbers speak. Int. J. Health Serv. 30 (2000) 873-877.

[33] R. Li, S. Pei, B. Chen, Y. Song, T. Zhang, W. Yang and J. Shaman, Substantial undocumented infection facilitates the rapid dissemination of novel coronavirus (SARS-CoV2). Science $\mathbf{3 6 8}$ (2020) eabb3221.

[34] J.A. Nelder and R. Mead, A simplex method for function minimization. Comput. J. 7 (1965) 308-313.

[35] H. Nishiura, N.M. Linton and A.R. Akhmetzhanov, Serial interval of novel coronavirus (COVID-19) infections. Int. J. Infect. Dis. 93 (2020) 284-286. 
[36] S. Palmer, From Popular Medicine to Medical Populism: Doctors, Healers, and Public Power in Costa Rica, 1800-1940. Duke University Press Books, Duke (2003).

[37] Panamá va un paso por delante en la respuesta al coronavirus. Available at: https://news.un.org/es/story/2020/03/1471462.

[38] M. Predescu, G. Sirbu, R. Levins and T. Awerbuch-Friedlander. On the dynamics of a deterministic and stochastic model for mosquito control. Appl. Math. Lett. 20 (2007) 919-925.

[39] R. Pung, C.J. Chiew, B.E. Young, S. Chin, M.I. Chen, H.E. Clapham, A.R. Cook, S. Maurer-Stroh, M. Toh, C. Poh, et al., Investigation of three clusters of COVID-19 in Singapore: implications for surveillance and response measures. Lancet 359 (2020) 1039-1046.

[40] L. Rosero-Bixby and W.H. Dow, Exploring why Costa Rica outperforms the United States in life expectancy: A tale of two inequality gradients. Proc. Natl. Acad. Sci. 113 (2016) 1130.

[41] Md.R. Sáenz, M. Acosta, J. Muiser and J.L. Bermúdez, Sistema de salud de Costa Rica. Salud Pública de México 5s (2011) s156-s167.

[42] P. Sandiford and M. Salvetto, Las desigualdades en salud en Panamá. Gac. Sanit. 16 (2002) 70-81.

[43] F. Sauma, Análisis de experiencias internacionales sobre sistemas nacionales de salud: el caso de Costa Rica. CEPAL, México (2013), 37.

[44] L. Scrucca, GA: A Package for Genetic Algorithms in R. J. Stat. Softw. 53 (2013) 37.

[45] H. Tian, Y. Liu, Y. Li, C.-H. Wu, B. Chen, M.U.G. Kraemer, B. Li, J. Cai, B. Xu and Q. Yang, An investigation of transmission control measures during the first 50 days of the COVID-19 epidemic in China. Science $\mathbf{3 6 8}$ (2020) eabb6105.

[46] R.N. Thompson, J.E. Stockwin, R.D. van Gaalen, J.A. Polonsky, Z.N. Kamvar, P.A. Demarsh, E. Dahlqwist, S. Li, E. Miguel, T. Jombart, et al., Improved inference of time-varying reproduction numbers during infectious disease outbreaks. Epidemics 29 (2019) 100356.

[47] J. Tolle, 87.65 Can growth be faster than exponential, and just how slow is the logarithm? Math. Gaz. 87 (2003) 522-525.

[48] C. Viboud, L. Simonsen and G. Chowell, A generalized-growth model to characterize the early ascending phase of infectious disease outbreaks. Epidemics 15 (2016) 27-37.

[49] V. Volpert, M. Banerjee and S. Petrovskii, On a quarantine model of coronavirus infection and data analysis. Math. Model. Nat. Phenom. 15 (2020) 24.

[50] R.G. Wallace, R. Kock, L. Bergmann, M. Gilbert, L. Hogerwerf, C. Pittiglio, R. Mattioli and R. Wallace, Did Neoliberalizing West African Forests Produce a New Niche for Ebola? Int. J. Health Serv. 46 (2016) 149-165.

[51] R. Wallace, L.F. Chaves, L. Bergmann, Cf.J. Ayres Lopes, L. Hogerwerf, R. Kock and R.G. Wallace, Clear-Cutting Disease Control: Capital-Led Deforestation, Public Health Austerity, and Vector-Borne Infection. Springer, New York (2018).

[52] A. Wilder-Smith and D.O. Freedman, Isolation, quarantine, social distancing and community containment: pivotal role for old-style public health measures in the novel coronavirus (2019-nCoV) outbreak. J. Travel Med. 27 (2020) taaa020.

[53] S. Woolhandler and D.U. Himmelstein, Intersecting U.S. Epidemics: Covid-19 and lack of health insurance. To appear in: Ann. Intern. Med. https://doi.org/10.7326/M20-1491 (2020).

[54] Z. Wu and J.M. McGoogan, Characteristics of and important lessons from the coronavirus disease 2019 (COVID-19) outbreak in China: summary of a report of 72314 cases from the Chinese Center for Disease Control and Prevention. JAMA 323 (2020) $1239-1242$.

[55] J.T. Wu, K. Leung, M. Bushman, N. Kishore, R. Niehus, P.M. de Salazar, B.J. Cowling, M. Lipsitch and G.M. Leung, Estimating clinical severity of COVID-19 from the transmission dynamics in Wuhan, China. Nat. Med. 26 (2020) 506-510.

[56] J.T. Wu, K. Leung and G.N. Leung, Nowcasting and forecasting the potential domestic and international spread of the 2019-nCoV outbreak originating in Wuhan, China: a modelling study. Lancet 395 (2020) 689-697.

[57] Ministerio de Planificación Nacional y Política Económica. Índice de desarrollo ssocial 2017. San José, CR: MIDEPLAN (2018).

[58] INEC. X Censo Nacional de Población y VI de Vivienda 2011: Resultados Generales. San José: Instituto Nacional de Estadísticas y Censos (2012). 